FERMILAB-TM-1889

\title{
Description and Calibration Beamline SEM/Ion Chamber Current Digitizer
}

\author{
Daniel Schoo \\ Fermi National Accelerator Laboratory \\ P.O. Box 500, Batavia, Illinois 60510
}

May 1994 


\section{Disclaimer}

This report was prepared as an account of work sponsored by an agency of the United States Government. Neither the United States Government nor any agency thereof, nor any of their employees, makes any warranty, express or implied, or assumes any legal liability or responsibility for the accuracy, completeness, or usefulness of any information, apparatus, product, or process disclosed, or represents that its use would not infringe privately owned rights. Reference herein to any specific commercial product, process, or service by trade name, trademark, manufacturer, or otherwise, does not necessarily constitute or imply its endorsement, recommendation, or favoring by the United States Government or any agency thereof. The views and opinions of authors expressed herein do not necessarily state or reflect those of the United States Government or any agency thereof. 
Description and Calibration

Beamline SEM/Ion Chamber Current Digitizer

Daniel Schoo

January 20, 1992 
Circuit Descriptions

Charge to Frequency Converter 1

Self Test 2

Integrated Intensity Radiation Interlock Comparators 2

Missing Pulse Detectors 3

Bias Voltage Monitor 4

Gate Generator/Quad TTL to NIM Level Converter 4

Testing and Calibration

Charge to Frequency Converter 5

Self Test 5

Integrated Intensity Radiation Interlock Comparators 5

Missing Pulse Detectors 6

Bias Voltage Monitor 6

Common Setup Procedures

Radiation Trip Setup $\quad 7$

Missing Pulse Detector $\quad 8$

Bias Voltage Monitor $\quad 8$

Summary of Fault Indications and Associated Causes

Missing Start 9

Missing Stop $\quad 9$

Radiation A,B $\quad 9$

Self Test $\quad 9$

Bias Voltage $\quad 9$

$\begin{array}{ll}\text { Display Clear } & 10\end{array}$

Summary of Input and Output Connections

Front Panel $\quad 11$

$\begin{array}{ll}\text { Back Panel } & 12\end{array}$

SEM Conversion Constant Table 13

Ion Chamber Conversion Constant Table 14

Hexadecimal to Decimal Conversion Table 15

$\begin{array}{ll}\text { Schematic Diagram } & 16\end{array}$ 


\section{MODULE DESCRIPTION}

The SEM/ Ion Chamber Current Digitizer converts a small input current into a frequency directly proportional to the amount of current. The current source can be a secondary emission monitor (SEM) or an ion chamber placed in a beam line to measure the particle beam flux. The output signal is a NIM level square wave that is applied to a totalizing counter. The counter is cleared immediately before the spill commences. The counting continues over the beam spill and the count at the end of spill is a direct integration of the total amount of beam flux that passed through the SEM or ion chamber.

The current digitizer contains circuits to generate a gate to control the totalizing counter using the accelerator clock timing signals. T5 opens the gate and resets the counter while T6 closes the gate and inhibits the counter. The GATE signal is NIM level and the RESET is TTL as required by a JORWAY 211 CAMAC quad scaler module.

Additional circuits for safety interlocks are incorporated to monitor the beam intensity and disable the beam should the intensity exceed a preset level. As required for safety related circuits, the circuitry that monitors the levels is redundant for enhanced protection against failure. Non redundant circuitry is self tested every machine cycle and the accelerator time pulse inputs are monitored for missing pulses.

\section{CIRCUIT DESCRIPTION}

Charge to Frequency Converter

The charge input of the module is sent through a $51 \mathrm{ohm}$ resistor followed by a .1 microfarad capacitor to ground. The resistor terminates the line impedance to minimize reflections of any high frequency energy present in the signal. The capacitor provides a low impedance AC ground for the termination, and helps to collect the charge for conversion by swamping out the distributed capacitance of the transmission line. A transient suppressor is connected across the capacitor to prevent arcs or static discharge from damaging the electronics. The charge is applied to the inverting input of the electrometer amplifier AD549K through a $100 \mathrm{~K}$ resistor. A 34 meg feedback resistor provides a conversion of 34E-06 volts per picocoulomb of charge per second.

The output from the electrometer is connected to the input of an AD537KD voltage to frequency converter through a low pass filter. The low pass filter consisting of a series $10 \mathrm{~K}$ resistor and a 10 uf capacitor to ground attenuates high frequency noise and stray AC hum in the signal. Additionally it integrates the intensity signal

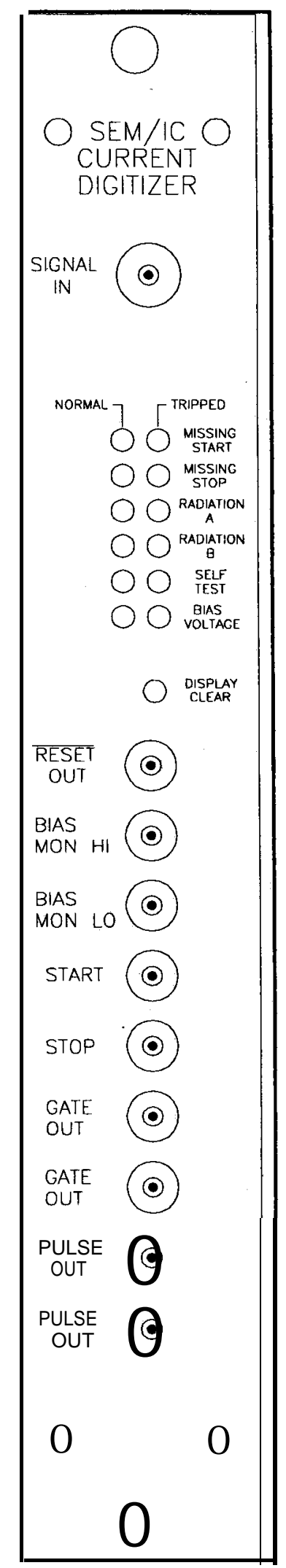


to collect and hold the charge from fast spills.

The $\mathrm{V} / \mathrm{F}$ is calibrated to an output frequency of approximately $11 \mathrm{KHz}$ per volt up to a maximum of $111 \mathrm{KHz}$. The conversion factor of a typical SEM is 1 picocoulomb of charge out per $3.333 \mathrm{E}+7$ protons. Overall this converts to a frequency of $11 \mathrm{KHz}$ per flux of $1 \mathrm{E} 12$ per second. The conversion factor of a typical ion chamber is 10 picocoulomb of charge out per $3.333 \mathrm{E}+7$ protons. Overall this converts to a frequency of $11 \mathrm{KHz}$ per flux of $1 \mathrm{E} 11$ per second. See the conversion charts at the end for specific details on proton flux, voltages and frequencies.

Self Test

The self test circuit tests the electrometer every accelerator cycle and operates immediately after T6. T6 triggers monostable U41A which times for 1 millisecond and provides a short delay to avoid tripping the intensity interlocks after a spill measurement. When U41A times out it triggers monostables U40A and U41B. U41B through buffer U35B operates relay RL7, the self test current relay, for 500 milliseconds. $\mathrm{U} 40 \mathrm{~A}$ provides a 250 millisecond delay for the electrometer to settle while a small test current is applied to the electrometer input through R38 and RL7. A voltage window comparator circuit consisting of buffer U17, comparators U18 and U19, and reference U20 measures the output from the electrometer and compares it against an upper limit of 10 volts and a lower limit of 9.5 volts. If the window comparator sees a voltage outside the limits, the output goes low. When U40A times out, U40B is triggered generating a 200 nanosecond sample pulse clocking latch U34A. The output from the window comparator is connected to the data input of latch U34A. U34A controls relay RL5, the SELF TEST FAIL relay, through buffer U35A. If the electrometer fails, the output of the window comparator will be low when U34A is clocked. The low is transferred to the output of U34A and the output of buffer U35A goes high dropping the relay and extinguishing the NORMAL LED. The output of U34A also pulls the CLEAR of U34B low making the output low and lighting the SELF TEST FAIL LED. The circuit clears itself at T6 following the first successful self test, picking up the relay and lighting the NORMAL LED. The trip status LED remains lit until manually reset to indicate to the operator that a trip has occurred and the nature of the trip.

Integrated Intensity Radiation Interlock Comparators

The output from the electrometer is also connected to two monitor circuits that integrate the voltage representing the beam flux and compare the level to a preset upper limit. I will describe only one since both circuits are identical and are duplicated for protection against single component failure.

The voltage signal from the electrometer is buffered by a unity gain inverting amplifier U7A. The output of the buffer is applied to the input of an integrator U7B with an integration constant of 1 second. Resetting of the integrator is controlled by a CMOS switch U9 which is driven by buffer U29B. The switch shorts the integration capacitor $\mathrm{C} 8$ beginning at $\mathrm{T} 6$ and continuing to $\mathrm{T} 5$. At $\mathrm{T} 5$ the switch opens and allows the integrator to integrate the voltage output from the electrometer. The resulting voltage at the output of the integrator is directly proportional to the total beamline particle flux. 
The output from the integrator is connected to a comparator U8. An adjustable reference voltage is applied to U8 which is supplied by U10. The comparator measures the total integrated flux and compares it to a preset limit. If the integrated flux exceeds the limit, the comparator output goes low and sets the PRESET of latch U27. U27 holds the trip status until T6 when the data is transferred to a second latch U28A. If the flux exceeded the limit, the output of U28A goes low pulling the CLEAR of U28B low lighting the RADIATION TRIP LED, and pulling the input of buffer U29A low. The output of U29A goes high dropping RL3, RADIATION TRIP A relay, and extinguishing the NORMAL LED. The circuit clears itself at T6 following the first spill below the intensity limit, picking up the relay and lighting the NORMAL LED. The trip status LED remains lit until manually reset to indicate to the operator that a trip has occurred and the nature of the trip.

\section{Missing Pulse Detectors}

There are two missing pulse detector circuits, one for T5 and one for T6. They monitor the accelerator timing pulses and generate a trip condition if no pulse is detected before a preset timeout period. I will describe only one since they are identical.

T5 is applied to the START input and is buffered by U42A. The pulse is directed to monostable U1A which is edge triggered. The monostable generates a pulse only if the state of the START input changes from low to high preventing a continuous high level on the input from being mistaken for a timing pulse. U1A generates a 1.5 second control pulse for U2, an eight bit presettable up/down counter. Since the counter preset is synchronous, the control pulse must be long enough to guarantee that a $1 \mathrm{~Hz}$ clock transition will occur during the preset pulse. The inverted output of U1A is connected to control input $\mathrm{S} 0$ of $\mathrm{U} 2$. The inverted output is also connected to $\mathrm{U} 39 \mathrm{C}$ which inverts the level and applies it to the S1 input of U2. The non inverted output of U1A was not used for this function because the timing skew between the $Q$ and $Q$ bar outputs could cause the counter to clear instead of preset if a $1 \mathrm{~Hz}$ clock transition happened to occur exactly at the same time as a preset pulse. When a pulse arrives triggering U1A, the S0 input is set low and the S1 input is set high. When the clock input on U2 goes high the counter is loaded to the setting of the delay setting switches into the counter. When U1A times out, S0 goes high and S1 goes low. This returns the counter to the count down mode. The counter is clocked by the $1 \mathrm{~Hz}$ astable oscillator U3, and counts down toward zero. If a timing pulse comes in before the count reaches zero, the counter is reloaded and starts over. If no pulse is received, the counter continues to count down and when it reaches zero generates a borrow pulse that pulls the CLEAR on latch U23A. The output of latch U23A goes low holding the status as the counter continues to count down. The counter underflows through zero to its maximum of 255 and counts down as long as no more pulses are detected. The output of U23A pulls the CLEAR of U23B low lighting the MISSING START LED, and pulling the input of buffer U24A low. The output of U24A goes high dropping RL1, the MISSING START relay, and extinguishing the NORMAL LED. The circuit clears itself when a T5 pulse is again detected by reloading the counter and presetting $\mathrm{U} 23 \mathrm{~A}$ back to a high state. Resetting picks up the relay and lights the NORMAL LED. The trip status LED remains lit until manually reset 
to indicate to the operator that a trip has occurred and the nature of the trip.

Bias Voltage Monitor

The bias voltage monitor is a related safety circuit that was packaged in the Current Digitizer module for convenience. The circuit measures the bias voltage applied to the beam monitoring device and compares it to preset upper and lower limits. If the voltage goes too high or low a trip condition is generated. A voltage divider at the SEM or ion chamber samples the bias voltage supply for the device and reduces the voltage by a factor of 100 . The sampled voltage is sent back differentially to the CD on a pair of RG 58 coax cables. Input protection is provided to the bias voltage monitor in case of a failure of the divider circuit.

The signal is connected to differential amplifier $\mathrm{U} 47$ which has unity gain and is used to provide ground isolation and immunity to common mode noise. The differential amplifier output is connected to a voltage window comparator circuit consisting of comparators $\mathrm{U} 44, \mathrm{U} 45$ and reference $\mathrm{U} 43$ that measures the bias voltage sample and compares it against preset limits. The upper limit is adjustable from 0 to 1 kilovolt and the lower limit is fixed at $20 \%$ below the upper limit. The set point is adjusted to $10 \%$ above the desired operating voltage and the window is + or $-10 \%$ If the window comparator sees a voltage outside the limits, the output goes low. At T6 the state of the window comparator is sampled by latch U37A. U37A is connected to latch U37B and buffer U38 which operate the same as the other relay/LED circuits. A trip causes RL6, the BIAS VOLTAGE FAIL relay, to drop. The bias voltage monitor resets itself at T6 after the bias voltage comes back into the correct range.

\section{Gate Generator and Quad TTL to NIM Level Converter}

The gate generator is a flip-flop of two NAND gates. It generates an alternate state output to gate the Quad Scaler module and is used by various circuits for internal timing control. It goes to a high state at T5 and low at T6. There are two identical gate generators for protection against single component failure.

The quad TTL to NIM level converter provides the proper voltage/current levels required for operation of the Quad Scaler module. Two separate identical buffered NIM GATE and PULSE TRAIN output signals are available.

The RESET output is a buffered inverted start pulse provided to clear the Quad Scaler module. The RESET is at TTL levels. 
TESTING and CALIBRATION

Charge to Frequency Converter

Install jumper blocks one each at JMP1, JMP2 and JMP3 in position "B". Apply power to the module but do not supply timing pulses. Allow the module to stabilize for 10 minutes. Connect the negative lead of a precision digital meter to the metal can of U15. Leave J1, the signal input, open and measure test point 4. Adjust R30, the electrometer offset pot, for a null of less than .1 millivolts. Connect a precision DC reference supply through a 100 megohm $1 \%$ resistor to the signal input J1. Set the reference to zero volts. Measure J9 the pulse train output with an oscilloscope and adjust $\mathrm{R} 34$ the V/F offset pot until the pulses stop. Set the reference to -1.000 volts. Measure the output frequency at $\mathrm{J} 9$ with a frequency counter and adjust R32, the V/F span pot, until the output is $3333.3 \mathrm{~Hz}$.

\section{Self Test}

Verify that nothing is connected to J1. Jumper pin 6 of RL7 to ground. Measure TP4 and verify a reading of between 9.6 and 9.9 volts. If not replace R38 with the next larger or smaller value depending on whether the voltage is too high or too low respectively. Measure J13, the ELECTROMETER OUT Lemo on the back panel and verify that the voltage out is the same as measured at TP4. Remove the jumper when the voltage is correct.

Integrated Intensity Radiation Interlock Comparators

Apply START and STOP timing pulses with the following parameters: START to STOP=15 seconds, STOP to START=15 seconds.

Connect a precision DC reference supply through a 100 megohm $1 \%$ resistor to the signal input J1. Set the reference to -3.00 volts. Measure TP 4 and verify a reading of 1.02 volts. Measure pin 7 of U7 with an oscilloscope. At the START pulse the voltage should be zero and begin to rise. The voltage should rise linearly and after 10 seconds should be at 10.2 volts and continuing to rise. At the STOP pulse the voltage should return to zero. Measure TP1 and adjust R11 for 5 volts. Monitor pin 5 of U27 with an oscilloscope. Set the input voltage reference to zero and wait two cycles for the second STOP pulse. The RADIATION TRIP A should read normal. At the second STOP pulse, apply -3.00 volts to the input. Monitor the oscilloscope, and at the next START pulse the level should be high. After 5 seconds the level should go low. At the following STOP pulse the RADIATION TRIP A should indicate a trip.

Repeat the procedure for channel B as follows:

Connect a precision DC reference supply through a 100 megohm $1 \%$ resistor to the signal input J1. Set the reference to -3.00 volts. Measure TP4 and verify a reading of 1.02 volts. Measure pin 7 of U11 with an oscilloscope. At the START pulse the voltage should be zero and begin to rise. The voltage should rise linearly and after 10 seconds should be at 10.2 volts and continuing to rise. At the STOP pulse the voltage should return to zero. Measure TP2 and adjust R20 to 5 volts. Monitor pin 5 of U30 with an oscilloscope. Set the input voltage reference to zero and wait two cycles for the second 
STOP pulse. The RADIATION TRIP B should read normal. At the second STOP pulse, apply -3.00 volts to the input. Monitor the oscilloscope, and at the next START pulse the level should be high. After 5 seconds the level should go low. At the following STOP pulse the RADIATION TRIP B should indicate a trip.

Missing Pulse Detectors

Set SW1 to F and SW2 to 0. Apply a START pulse. The MISSING START status should be normal and after 15 seconds trip to a fail. Apply another START pulse. The MISSING START should clear to normal.

Set SW3 to F and SW4 to 0. Apply a STOP pulse. The MISSING STOP should be normal and after 15 seconds trip to a fail. Apply another STOP pulse. The MISSING STOP should clear to normal.

The delay settings on the missing pulse detectors are set in hexadecimal notation. To set the switches for normal operation, refer to the hexadecimal to decimal conversion chart at the end of this manual and set the switches to the desired delay. The delay should be set to twice the expected accelerator cycle time. SW2 is the most significant digit and SW1 is the least significant digit for the START detector. SW4 is the most significant digit and SW3 is the least significant digit for the STOP detector.

Bias Voltage Monitor

Apply START and STOP pulses as you did above when calibrating the integrated intensity Interlock comparators. Measure TP3 and adjust R66 to 8.8 volts. Connect a DC reference to the BIAS MONITOR inputs, - to J3 and + to J4. Set the input to 8 volts. Following the next STOP pulse the BIAS VOLTAGE FAIL should be normal. Set the input voltage to 7.1 volts. At the next STOP pulse the BIAS VOLTAGE FAIL should be tripped. Set the input to 8.9 volts. At the next STOP pulse the BIAS VOLTAGE FAIL should be tripped. Set the input voltage to 8 volts. At the next STOP pulse the BIAS VOLTAGE FAIL should be normal. 
Radiation Trip Setup

\section{Common Setup Procedures}

To set up the radiation trip levels, determine the type of detector to be used, either a SEM or an ion chamber. Refer to the SEM or IC Conversion Constants chart at the end of this document depending the detector to be used. Look up the PROTON FLUX level you want to limit to. Move across to the ELECTROMETER OUT column and read the voltage listed there. Set the trip level adjustments to the ELECTROMETER OUT voltage listed in the chart. If the level is not listed, divide a lower value of flux that is listed into your desired value and multiply the ELECTROMETER OUT voltage listing for the lower value by the result.

Setup Examples:

To set the Radiation Trip to $1 \mathrm{E}+11$ protons maximum using a SEM: The ELECTROMETER OUT is listed as 102 millivolts for $1 \mathrm{E}+11$. Measure TP1 and adjust R11 to .102 Volts. Measure TP2 and adjust R20 to .102 volts.

To set the Radiation Trip to $4 \mathrm{E}+11$ protons maximum using a SEM: The ELECTROMETER OUT is listed as 102 millivolts for $1 \mathrm{E}+11$, four times that is 408 millivolts. Measure TP1 and adjust R11 to .408 Volts. Measure TP2 and adjust R20 to .408 volts.

To set the Radiation Trip to $2 \mathrm{E}+12$ protons maximum using a SEM: The ELECTROMETER OUT is listed as 1.02 volts for $1 \mathrm{E}+12$, twice that is 2.04 volts. Measure TP1 and adjust R11 to 2.04 Volts. Measure TP2 and adjust R20 to 2.04 volts.

To set the Radiation Trip to $1 \mathrm{E}+8$ protons maximum using an IC: The ELECTROMETER OUT is listed as 1.02 millivolts for $1 \mathrm{E}+8$. Measure TP1 and adjust R11 to 1.02 millivolts. Measure TP2 and adjust R20 to 1.02 millivolts. 
Missing Pulse Detector

The missing pulse detectors are usually set up for a delay of about twice the Accelerator cycle time from one T5 to the next T5 pulse. The settings are done in hexadecimal notation. To setup the delay times in decimal seconds, refer to the Hexadecimal to Decimal Conversion chart at the end of this manual. Look up the desired time in one of the DEC columns and read the HEX column next to it for the hex equivalent. Set the rotary switches S1, S2, S3, and S4 to the hex value.

Setup Examples:

For a delay of 46 seconds, the HEX equivalent is 2E. Set SW2 to 2 and SW1 to E, and SW4 to 2 and SW3 to E

For a delay of 65 seconds, the HEX equivalent is 41 . Set SW2 to 4 and SW1 to 1, SW4 to 4 and SW3 to 1

Bias Voltage Monitor

To set the bias voltage monitor, determine the operating voltage of the chamber to be used. Divide this value by 100 and add 10\%. Measure TP3 and adjust R66 to the calculated voltage.

Setup Examples:

For an Ion Chamber operating at 800 volts.

$800 \mathrm{~V} / 100=8$

$10 \%$ of $8=.8$

$8+.8=8.8 \mathrm{~V}$ Adjust $\mathrm{R} 66$ to 8.8 volts

For a SEM operating at 150 volts.

$150 \mathrm{~V} / 100=1.5$

$10 \%$ of $1.5=.15$

$1.5+.15=1.65 \mathrm{~V}$ Adjust R66 to 1.65 volts 
The fault indicators are latched. When a fault occurs the NORMAL light goes out and the TRIPPED light comes on. With the exception of MISSING START all faults clear automatically at the reception of a STOP pulse when the conditions that caused the fault return to normal. MISSING START clears at the reception of a START pulse. When a particular fault has cleared, the NORMAL light comes on but the TRIPPED light stays lit to indicate that a fault condition had been present but is now normal. When an operator has visited and inspected the module and noted the fault, then the TRIPPED indication can be cleared manually by pushing the DISPLAY CLEAR button. All faults with the exception of MISSING START and MISSING STOP take effect at the next STOP pulse. This is to prevent an abortion of the beam during spill. MISSING STOP and MISSING START take effect immediately since under this condition the time of the spill is unknown. See page one for a layout of the display and connection locations.

MISSING START-- A START timing pulse has not been received within the expected amount of time. This means that $\mathrm{T} 5$ has not been received by the module before a preset timeout period of about two accelerator cycles long. Clears at the reception of a START pulse.

MISSING STOP-- A STOP timing pulse has not been received within the expected amount of time. This means that $\mathrm{T} 6$ has not been received by the module before a preset timeout period of about two accelerator cycles long. If both MISSING STOP and MISSING START are faulted then either the clock is missing or the clock pulse decoder CAMAC module such as an 096 is bad. Clears at the reception of a STOP pulse.

RADIATION A-- The intensity of the beam has exceeded the preset limit for at least one pulse. Clears at the first STOP pulse following a spill less than the limit.

RADIATION B-- The same as A. B channel is a redundant backup for A.

SELF TEST-- The module has detected an error in the non spill time test voltages internally. This could be caused by a failure of a component in the module, or by a problem with the SEM or associated cabling. To determine which, disconnect the signal input lead to the module and wait for two accelerator cycles to go by. If the fault clears, the problem is with the SEM or cabling. A shorted SEM signal cable, a SEM that is ground faulted to its mounting, or a SEM that is breaking down will cause a self test failure. If the fault does not clear the module has failed. Clears at the first STOP pulse following a successful self test.

BIAS VOLTAGE-- The bias voltage supply to the SEM is too high or too low. The usual operating bias is -800 volts. A level other than plus or minus $10 \%$ of this voltage will cause a trip. The most likely cause is a failure of the high voltage bias supply. The bias voltage is sampled by a 100 to 1 voltage divider connected at the SEM. If the power 
supply is normal check the divider and wiring. There should be about -8 volts measured from BIAS MON HIGH (plus meter lead) to BIAS MON LOW (minus meter lead). Clears at the first STOP pulse following a measurement of normal bias voltage.

DISPLAY CLEAR-- This pushbutton clears the latched fault status on the display. It has no effect whatsoever on the faults or condition of the module, it only turns off the TRIPPED indicator lights after they have been noted and the status is currently normal. TRIPPED lights will immediately relight after releasing the clear button for faults that are still present. 


\section{Summary of Input and Output Connections}

\section{FRONT PANEL}

RESET OUT-- This is a TTL low true output that is used with a 211 Quad Scaler module. This signal is connected to the 211 reset input.

BIAS MON HIGH, BIAS MON LOW-- This is a differential analog input pair that is used to monitor the bias voltage on the SEM or ion chamber. The high voltage is divided down to a safe level by a resistor network located at the SEM or ion chamber and applied to these inputs.

START-- This is a high true TTL input that is used to trigger the module to start a measurement cycle. The input is normally $\mathrm{T} 5$.

STOP-- This is a high true TTL input that is used to trigger the module to end a measurement cycle and transfer the status of the faults to the status and interlock outputs. The self test cycle is also done beginning at the STOP pulse. The input is normally $\mathrm{T} 6$.

GATE OUT-- There are two identical separately buffered NIM level gate signals. The GATE OUT is used with a 211 Quad Scaler module to control the counting of the pulses only during spill. The GATE OUT is connected to the INHIBIT input of the 211. The GATE OUT goes low at the reception of a START and high at the reception of a STOP pulse.

PULSE OUT-- There are two identical separately buffered NIM level pulse train outputs. The pulse frequency from START to STOP represents the amount of current and therefore the beam intensity applied to the SIGNAL IN. Immediately following the STOP pulse is a self test cycle during which the pulse train jumps to a high frequency for 500 milliseconds and then settles back to the normal level. The PULSE OUT is normally connected to an INPUT of a 211 CAMAC module. 


\section{BACK PANEL}

STATUS-- A Burndy GOB 12-88 PNE, eight pin connector is mounted on the back of the module to provide for remote status of each of the fault conditions. There is one normally closed low current relay contact for each of six faults. Each contact opens to indicate a trip condition. The pins are connected as follows:
A--Missing Start
B--Missing Stop
E--Self Test Fail
F--Bias Voltage Fail
C--Rad Trip A
D--Rad Trip B
G--Status Common

ELECTROMETER OUT-- A Lemo connector mounted on the back of the module between the STATUS and INTERLOCK connectors. A buffered signal from the output of the electrometer is available primarily for testing and troubleshooting. This signal can be used in special cases where an analog signal is desired instead of or in addition to a pulse train.

INTERLOCK-- A Burndy GOB 10-4 SNE, four pin connector is mounted on the back of the module to provide for remote status to the beamline safety interlock system.

In the usual configuration, the A LOOP interlock trips with any of the following faults: MISSING START, RADIATION A, SELF TEST

In the usual configuration, the B LOOP interlock trips with any of the following faults: MISSING STOP, RADIATION B, BIAS VOLTAGE

The connector pins are assigned as follows:

$\begin{array}{ll}\text { A--Supply Common } & \text { B--A Loop Interlock (Normal }=-12 \text { Volts, Tripped }=0 \text { Volts) } \\ \text { C--Supply Common } & \text { D--B Loop Interlock (Normal }=-12 \text { Volts, Tripped }=0 \text { Volts) }\end{array}$ 
SEM Conversion Constants

SEM/IC Current Digitizer

\section{CALIBRATION}

\section{TEST INPUT}

\section{$3.00 \mathrm{uV}$}

$10.0 \mathrm{uV}$

$15.0 \mathrm{uV}$

$30.0 \mathrm{uV}$

$100 \mathrm{uV}$

$150 \mathrm{uV}$

$300 \mathrm{uV}$

$1.0 \mathrm{mV}$

$1.5 \mathrm{mV}$

$3.0 \mathrm{mV}$

$10.0 \mathrm{mV}$

$15.0 \mathrm{mV}$

$30.0 \mathrm{mV}$

$100 \mathrm{mV}$

$150 . \mathrm{mV}$

$300 \mathrm{mV}$

$1.0 \mathrm{~V}$

$1.5 \mathrm{~V}$

$3.0 \mathrm{~V}$

$10.0 \mathrm{~V}$

$15.0 \mathrm{~V}$

$30.0 \mathrm{~V}$

PROTON FLUX
$1 E+06 /$ Second
$3.33 E+06 / S$
$5 E+06 / S$
$1 E+07 / S$
$3.33 E+7 / S$
$5 E+07 / S$
$1 E+08 / S$
$3.33 E+8 / S$
$5 E+08 / S$
$1 E+09 / S$
$3.33 E+9 / S$
$5 E+09 / S$
$1 E+010 / S$
$3.33 E+10 / S$
$5 E+010 / S$
$1 E+011 / S$
$3.33 E+11 / S$
$5 E+011 / S$
$1 E+012 / S$
$3.33 E+12 / S$
$5 E+012 / S$
$1 E+013 / S$

$\begin{array}{ll}\text { SEM CHARGE OUT } & \text { ELECTROMETER OUT } \\ 30.0 \mathrm{femtoColoumbs} & 1.02 \mathrm{microVolts} \\ 100 \mathrm{fC} & 3.40 \mathrm{uV} \\ 150 \mathrm{fC} & 5.10 \mathrm{uV} \\ 300 \mathrm{fC} & 10.20 \mathrm{uV} \\ 1.0 \mathrm{pC} & 34.00 \mathrm{uV} \\ 1.5 \mathrm{pC} & 51.00 \mathrm{uV} \\ 3.0 \mathrm{pC} & 102.0 \mathrm{uV} \\ 10.0 \mathrm{pC} & 340.0 \mathrm{uV} \\ 15.0 \mathrm{pC} & 510.0 \mathrm{uV} \\ 30.0 \mathrm{pC} & 1.020 \mathrm{mV} \\ 100 \mathrm{pC} & 3.400 \mathrm{mV} \\ 150 \mathrm{pC} & 5.100 \mathrm{mV} \\ 300 \mathrm{pC} & 10.20 \mathrm{mV} \\ 1.0 \mathrm{nC} & 34.00 \mathrm{mV} \\ 1.5 \mathrm{nC} & 51.00 \mathrm{mV} \\ 3.0 \mathrm{nC} & 102 \mathrm{mV} \\ 10.0 \mathrm{nC} & 340 \mathrm{mV} \\ 15.0 \mathrm{nC} & 510 \mathrm{mV} \\ 30.0 \mathrm{nC} & 1.02 \mathrm{~V} \\ 100 \mathrm{nC} & 3.40 \mathrm{~V} \\ 150 \mathrm{nC} & 5.10 \mathrm{~V} \\ 300 \mathrm{nC} & 10.2 \mathrm{~V}\end{array}$

RAD INTERLOCK

INTEGRATOR OUT

(1)1SEC @23SEC

$1.02 \mathrm{uV} \quad 23.46 \mathrm{uV}$

$3.40 \mathrm{uV} \quad 78.20 \mathrm{uV}$

$5.1 \mathrm{uV} \quad 117.3 \mathrm{uV}$

$10.2 \mathrm{uV} \quad 234.6 \mathrm{uV}$

$34 \mathrm{uV} \quad 782.0 \mathrm{uV}$

$51.0 \mathrm{uV} \quad 1.173 \mathrm{mV}$

$102.0 \mathrm{uV} \quad 2.346 \mathrm{mV}$

$340.0 \mathrm{uV} \quad 7.820 \mathrm{mV}$

$510.0 \mathrm{uV} \quad 11.73 \mathrm{mV}$

$1.020 \mathrm{mV} \quad 23.46 \mathrm{mV}$

$3.400 \mathrm{mV} \quad 78.20 \mathrm{mV}$

$5.100 \mathrm{mV} \quad 117.3 \mathrm{mV}$

$10.20 \mathrm{mV} \quad 234.6 \mathrm{mV}$

$34.00 \mathrm{mV} \quad 782.0 \mathrm{mV}$

$51.00 \mathrm{mV} \quad 1.173 \mathrm{~V}$

$102 \mathrm{mV}$

$340 \mathrm{mV}$

$510 \mathrm{mV}$

$1.02 \mathrm{~V}$

$3.40 \mathrm{~V}$

$5.10 \mathrm{~V}$

$10.2 \mathrm{~V}$
$1.173 \mathrm{~V}$
$2.346 \mathrm{~V}$

$7.820 \mathrm{~V}$

$11.73 \mathrm{~V}$

$23.46 \mathrm{~V}^{*}$

$78.20 \mathrm{~V}^{*}$

$117.3 \mathrm{~V}^{*}$

$234.6 \mathrm{~V}^{*}$
OUTPUT

FREQUENCY COUNTS

HERTZ

$.0111 \mathrm{~Hz}$

$.0333 \mathrm{~Hz}$

$.0555 \mathrm{~Hz}$

$.1111 \mathrm{~Hz}$

$.3333 \mathrm{~Hz}$

$.5555 \mathrm{~Hz}$

$1.111 \mathrm{~Hz}$

$3.333 \mathrm{~Hz}$

$5.555 \mathrm{~Hz}$

$11.11 \mathrm{~Hz}$

$33.33 \mathrm{~Hz}$

$55.55 \mathrm{~Hz}$

$111.1 \mathrm{~Hz}$

$333.3 \mathrm{~Hz}$

$555.5 \mathrm{~Hz}$

$1.111 \mathrm{KHz}$

$3.333 \mathrm{KHz}$

$5.555 \mathrm{KHz}$

$11.11 \mathrm{KHz}$

$33.33 \mathrm{KHz}$

$55.55 \mathrm{KHz}$

$111.1 \mathrm{KHz}$
@23SEC

0.26

0.77

1.28

2.56

7.66

27

25

127

766

2555

7666

12777

25555

76666

127777

255555

766666

1277777

2555555

NOTES:

-Calibration Test Input voltages are applied to the SIGNAL INPUT with a 100 Meg resistor in series to simulate the signal from a SEM.

-The SEM Charge Out is the average output from a typical SEM operating at a bias potential of -800 Volts.

-The electrometer voltage out is given assuming a $34 \mathrm{Meg}$ feedback resistor.

*It is beyond the capability of parts of the circuit to operate up to these levels. 
IC Conversion Constants

SEM/IC Current Digitizer

\section{CALIBRATION TEST INPUT}

$3.00 \mathrm{uV}$

$10.0 \mathrm{uV}$

$15.0 \mathrm{uV}$

$30.0 \mathrm{uV}$

$100 \mathrm{uV}$

$150 \mathrm{uV}$

$300 \mathrm{uV}$

$1.0 \mathrm{mV}$

$1.5 \mathrm{mV}$

$3.0 \mathrm{mV}$

$10.0 \mathrm{mV}$

$15.0 \mathrm{mV}$

$30.0 \mathrm{mV}$

$100 \mathrm{mV}$

$150 \mathrm{mV}$

$300 \mathrm{mV}$

$1.0 \mathrm{~V}$

$1.5 \mathrm{~V}$

$3.0 \mathrm{~V}$

$10.0 \mathrm{~V}$

$15.0 \mathrm{~V}$

$30.0 \mathrm{~V}$

PROTON FLUX
$1 \mathrm{E}+05 /$ Second
$3.33 \mathrm{E}+05 / \mathrm{S}$
$5 \mathrm{E}+05 / \mathrm{S}$
$1 \mathrm{E}+06 / \mathrm{S}$
$3.33 \mathrm{E}+6 / \mathrm{S}$
$5 \mathrm{E}+06 / \mathrm{S}$
$1 \mathrm{E}+07 / \mathrm{S}$
$3.33 \mathrm{E}+7 / \mathrm{S}$
$5 \mathrm{E}+07 / \mathrm{S}$
$1 \mathrm{E}+08 / \mathrm{S}$
$3.33 \mathrm{E}+8 / \mathrm{S}$
$5 \mathrm{E}+08 / \mathrm{S}$
$1 \mathrm{E}+09 / \mathrm{S}$
$3.33 \mathrm{E}+9 / \mathrm{S}$
$5 \mathrm{E}+09 / \mathrm{S}$
$1 \mathrm{E}+010 / \mathrm{S}$
$3.33 \mathrm{E}+10 / \mathrm{S}$
$5 \mathrm{E}+010 / \mathrm{S}$
$1 \mathrm{E}+011 / \mathrm{S}$
$3.33 \mathrm{E}+11 / \mathrm{S}$
$5 \mathrm{E}+011 / \mathrm{S}$
$1 \mathrm{E}+012 / \mathrm{S}$

IC CHARGE OUT
$30.0 \mathrm{fem}$ toColoumbs
$100 \mathrm{fC}$
$150 \mathrm{fC}$
$300 \mathrm{fC}$
$1.0 \mathrm{pC}$
$1.5 \mathrm{pC}$
$3.0 \mathrm{pC}$
$10.0 \mathrm{pC}$
$15.0 \mathrm{pC}$
$30.0 \mathrm{pC}$
$100 \mathrm{pC}$
$150 \mathrm{pC}$
$300 \mathrm{pC}$
$1.0 \mathrm{nC}$
$1.5 \mathrm{nC}$
$3.0 \mathrm{nC}$
$10.0 \mathrm{nC}$
$15.0 \mathrm{nC}$
$30.0 \mathrm{nC}$
$100 \mathrm{nC}$
$150 \mathrm{nC}$
$300 \mathrm{nC}$

\begin{tabular}{lllll} 
& \multicolumn{2}{l}{ RAD INTERLOCK } & \multicolumn{2}{l}{ OUTPUT } \\
ELECTROMETER OUT & INTEGRATOR OUT & \multicolumn{1}{l}{ FREQUENCY } & COUNTS \\
$1.02 \mathrm{microVolts}$ & @1SEC & @23SEC & HERTZ & @23SEC \\
$3.40 \mathrm{uV}$ & $1.02 \mathrm{uV}$ & $23.46 \mathrm{uV}$ & $.0111 \mathrm{~Hz}$ & 0.26 \\
$5.10 \mathrm{uV}$ & $3.40 \mathrm{uV}$ & $78.20 \mathrm{uV}$ & $.0333 \mathrm{~Hz}$ & 0.77 \\
$10.20 \mathrm{uV}$ & $5.1 \mathrm{uV}$ & $117.3 \mathrm{uV}$ & $.0555 \mathrm{~Hz}$ & 1.28 \\
$34.00 \mathrm{uV}$ & $10.2 \mathrm{uV}$ & $234.6 \mathrm{uV}$ & $.1111 \mathrm{~Hz}$ & 2.56 \\
$51.00 \mathrm{uV}$ & $34 \mathrm{uV}$ & $782.0 \mathrm{uV}$ & $.3333 \mathrm{~Hz}$ & 7.66 \\
$102.0 \mathrm{uV}$ & $51.0 \mathrm{uV}$ & $1.173 \mathrm{mV}$ & $.5555 \mathrm{~Hz}$ & 12.7 \\
$340.0 \mathrm{uV}$ & $102.0 \mathrm{uV}$ & $2.346 \mathrm{mV}$ & $1.111 \mathrm{~Hz}$ & 25 \\
$510.0 \mathrm{uV}$ & $340.0 \mathrm{uV}$ & $7.820 \mathrm{mV}$ & $3.333 \mathrm{~Hz}$ & 76 \\
$1.020 \mathrm{mV}$ & $510.0 \mathrm{uV}$ & $11.73 \mathrm{mV}$ & $5.555 \mathrm{~Hz}$ & 127 \\
$3.400 \mathrm{mV}$ & $1.020 \mathrm{mV}$ & $23.46 \mathrm{mV}$ & $11.11 \mathrm{~Hz}$ & 255 \\
$5.100 \mathrm{mV}$ & $3.400 \mathrm{mV}$ & $78.20 \mathrm{mV}$ & $33.33 \mathrm{~Hz}$ & 766 \\
$10.20 \mathrm{mV}$ & $5.100 \mathrm{mV}$ & $117.3 \mathrm{mV}$ & $55.55 \mathrm{~Hz}$ & 1277 \\
$34.00 \mathrm{mV}$ & $10.20 \mathrm{mV}$ & $234.6 \mathrm{mV}$ & $111.1 \mathrm{~Hz}$ & 2555 \\
$51.00 \mathrm{mV}$ & $34.00 \mathrm{mV}$ & $782.0 \mathrm{mV}$ & $333.3 \mathrm{~Hz}$ & 7666 \\
$102 \mathrm{mV}$ & $51.00 \mathrm{mV}$ & $1.173 \mathrm{~V}$ & $555.5 \mathrm{~Hz}$ & 12777 \\
$340 \mathrm{mV}$ & $102 \mathrm{mV}$ & $2.346 \mathrm{~V}$ & $1.111 \mathrm{KHz}$ & 25555 \\
$510 \mathrm{mV}$ & $340 \mathrm{mV}$ & $7.820 \mathrm{~V}$ & $3.333 \mathrm{KHz}$ & 76666 \\
$1.02 \mathrm{~V}$ & $510 \mathrm{mV}$ & $11.73 \mathrm{~V}$ & $5.555 \mathrm{KHz}$ & 127777 \\
$3.40 \mathrm{~V}$ & $1.02 \mathrm{~V}$ & $23.46 \mathrm{~V}$ & $11.11 \mathrm{KHz}$ & 255555 \\
$5.10 \mathrm{~V}$ & $3.40 \mathrm{~V}$ & $78.20 \mathrm{~V}$ & $33.33 \mathrm{KHz}$ & 766666 \\
$10.2 \mathrm{~V}$ & $5.10 \mathrm{~V}$ & $117.3 \mathrm{~V}$ & $55.55 \mathrm{KHz}$ & 1277777 \\
& $10.2 \mathrm{~V}$ & $234.6 \mathrm{~V}$ & $111.1 \mathrm{KHz}$ & 2555555
\end{tabular}

\begin{tabular}{lllll} 
& \multicolumn{2}{l}{ RAD INTERLOCK } & \multicolumn{2}{l}{ OUTPUT } \\
ELECTROMETER OUT & INTEGRATOR OUT & \multicolumn{1}{l}{ FREQUENCY } & COUNTS \\
$1.02 \mathrm{microVolts}$ & @1SEC & @23SEC & \multicolumn{1}{l}{ HERTZ } & $@ 235 E C$ \\
$3.40 \mathrm{uV}$ & $1.02 \mathrm{uV}$ & $23.46 \mathrm{uV}$ & $.0111 \mathrm{~Hz}$ & 0.26 \\
$5.10 \mathrm{uV}$ & $3.40 \mathrm{uV}$ & $78.20 \mathrm{uV}$ & $.0333 \mathrm{~Hz}$ & 0.77 \\
$10.20 \mathrm{uV}$ & $5.1 \mathrm{uV}$ & $117.3 \mathrm{uV}$ & $.0555 \mathrm{~Hz}$ & 1.28 \\
$34.00 \mathrm{uV}$ & $10.2 \mathrm{uV}$ & $234.6 \mathrm{uV}$ & $.1111 \mathrm{~Hz}$ & 2.56 \\
$51.00 \mathrm{uV}$ & $34 \mathrm{uV}$ & $782.0 \mathrm{uV}$ & $.3333 \mathrm{~Hz}$ & 7.66 \\
$102.0 \mathrm{uV}$ & $51.0 \mathrm{uV}$ & $1.173 \mathrm{mV}$ & $.5555 \mathrm{~Hz}$ & 12.7 \\
$340.0 \mathrm{uV}$ & $102.0 \mathrm{uV}$ & $2.346 \mathrm{mV}$ & $1.111 \mathrm{~Hz}$ & 25 \\
$510.0 \mathrm{uV}$ & $340.0 \mathrm{uV}$ & $7.820 \mathrm{mV}$ & $3.333 \mathrm{~Hz}$ & 76 \\
$1.020 \mathrm{mV}$ & $510.0 \mathrm{uV}$ & $11.73 \mathrm{mV}$ & $5.555 \mathrm{~Hz}$ & 127 \\
$3.400 \mathrm{mV}$ & $1.020 \mathrm{mV}$ & $23.46 \mathrm{mV}$ & $11.11 \mathrm{~Hz}$ & 255 \\
$5.100 \mathrm{mV}$ & $3.400 \mathrm{mV}$ & $78.20 \mathrm{mV}$ & $33.33 \mathrm{~Hz}$ & 766 \\
$10.20 \mathrm{mV}$ & $5.100 \mathrm{mV}$ & $117.3 \mathrm{mV}$ & $55.55 \mathrm{~Hz}$ & 1277 \\
$34.00 \mathrm{mV}$ & $10.20 \mathrm{mV}$ & $234.6 \mathrm{mV}$ & $111.1 \mathrm{~Hz}$ & 2555 \\
$51.00 \mathrm{mV}$ & $34.00 \mathrm{mV}$ & $782.0 \mathrm{mV}$ & $333.3 \mathrm{~Hz}$ & 7666 \\
$102 \mathrm{mV}$ & $51.00 \mathrm{mV}$ & $1.173 \mathrm{~V}$ & $555.5 \mathrm{~Hz}$ & 12777 \\
$340 \mathrm{mV}$ & $102 \mathrm{mV}$ & $2.346 \mathrm{~V}$ & $1.111 \mathrm{KHz}$ & 25555 \\
$510 \mathrm{mV}$ & $340 \mathrm{mV}$ & $7.820 \mathrm{~V}$ & $3.333 \mathrm{KHz}$ & 76666 \\
$1.02 \mathrm{~V}$ & $510 \mathrm{mV}$ & $11.73 \mathrm{~V}$ & $5.555 \mathrm{KHz}$ & 127777 \\
$3.40 \mathrm{~V}$ & $1.02 \mathrm{~V}$ & $23.46 \mathrm{~V}$ & $11.11 \mathrm{KHz}$ & 255555 \\
$5.10 \mathrm{~V}$ & $3.40 \mathrm{~V}$ & $78.20 \mathrm{~V}$ & $33.33 \mathrm{KHz}$ & 766666 \\
$10.2 \mathrm{~V}$ & $5.10 \mathrm{~V}$ & $117.3 \mathrm{~V}$ & $55.55 \mathrm{KHz}$ & 1277777 \\
& $10.2 \mathrm{~V}$ & $234.6 \mathrm{~V}$ & $111.1 \mathrm{KHz}$ & 2555555
\end{tabular}

NOTES:

-Calibration Test Input voltages are applied to the SIGNAL INPUT with a $100 \mathrm{Meg}$ resistor in series to simulate the signal from an ion chamber.

- The ion chamber Charge Out is the average output from a typical ion chamber operating at a bias potential of -800 Volts.

-The electrometer voltage out is given assuming a $34 \mathrm{Meg}$ feedback resistor.

*It is beyond the capability of parts of the circuit to operate up to these levels. 
Hexadecimal to Decimal Conversion

SEM/Ion Chamber Current Digitizer

\begin{tabular}{|c|c|c|c|c|c|c|c|c|c|c|c|c|c|c|c|}
\hline HEX & DEC & HEX & DEC & HEX & DEC & HEX & DEC & HEX & DEC & HEX & DEC & HEX & DEC & HEX & DEC \\
\hline 00 & 00 & 23 & 35 & 46 & 70 & 69 & 105 & $8 B$ & 140 & $\mathrm{AE}$ & 175 & $\mathrm{D} 2$ & 210 & F5 & 245 \\
\hline 01 & 01 & 24 & 36 & 47 & 71 & $6 \mathrm{~A}$ & 106 & $8 C$ & 141 & $\mathrm{AF}$ & 176 & D3 & 211 & F6 & 246 \\
\hline 02 & 02 & 25 & 37 & 48 & 72 & $6 \mathrm{~B}$ & 107 & $8 \mathrm{D}$ & 142 & $\mathrm{BO}$ & 177 & D4 & 212 & F7 & 247 \\
\hline 03 & 03 & 26 & 38 & 49 & 73 & $6 C$ & 108 & $8 \mathrm{E}$ & 143 & B1 & 178 & D5 & 213 & F8 & 248 \\
\hline 04 & 04 & 27 & 39 & $4 \mathrm{~A}$ & 74 & $6 \mathrm{D}$ & 109 & $8 \mathrm{~F}$ & 144 & B2 & 179 & D6 & 214 & F9 & 249 \\
\hline 05 & 05 & 28 & 40 & $4 B$ & 75 & $6 \mathrm{E}$ & 110 & 90 & 145 & B3 & 180 & D7 & 215 & FA & 250 \\
\hline 06 & 06 & 29 & 41 & $4 C$ & 76 & $6 \mathrm{~F}$ & 111 & 91 & 146 & B4 & 181 & D8 & 216 & FB & 251 \\
\hline 07 & 07 & $2 \mathrm{~A}$ & 42 & $4 \mathrm{D}$ & 77 & 70 & 112 & 92 & 147 & B5 & 182 & D9 & 217 & $\mathrm{FC}$ & 252 \\
\hline 08 & 08 & $2 B$ & 43 & $4 E$ & 78 & 71 & 113 & 93 & 148 & B6 & 183 & $\mathrm{DA}$ & 218 & $\mathrm{FD}$ & 253 \\
\hline 09 & 09 & $2 C$ & 44 & $4 \mathrm{~F}$ & 79 & 72 & 114 & 94 & 149 & B7 & 184 & DB & 219 & $\mathrm{FE}$ & 254 \\
\hline $0 \mathrm{~A}$ & 10 & $2 \mathrm{D}$ & 45 & 50 & 80 & 73 & 115 & 95 & 150 & B8 & 185 & $D C$ & 220 & $\mathrm{FF}$ & 255 \\
\hline $\mathrm{OB}$ & 11 & $2 \mathrm{E}$ & 46 & 51 & 81 & 74 & 116 & 96 & 151 & B9 & 186 & DD & 221 & & \\
\hline$O C$ & 12 & $2 \mathrm{~F}$ & 47 & 52 & 82 & 75 & 117 & 97 & 152 & BA & 187 & $\mathrm{DE}$ & 222 & & \\
\hline $0 \mathrm{D}$ & 13 & 30 & 48 & 53 & 83 & 76 & 118 & 98 & 153 & BB & 188 & DF & 223 & & \\
\hline $0 \mathrm{E}$ & 14 & 31 & 49 & 54 & 84 & 77 & 119 & 99 & 154 & $\mathrm{BC}$ & 189 & E0 & 224 & & \\
\hline $\mathrm{OF}$ & 15 & 32 & 50 & 55 & 85 & 78 & 120 & $9 \mathrm{~A}$ & 155 & $\mathrm{BD}$ & 190 & E1 & 225 & & \\
\hline 10 & 16 & 33 & 51 & 56 & 86 & 79 & 121 & $9 \mathrm{~B}$ & 156 & $\mathrm{BE}$ & 191 & E2 & 226 & & \\
\hline 11 & 17 & 34 & 52 & 57 & 87 & $7 \mathrm{~A}$ & 122 & $9 \mathrm{C}$ & 157 & $\mathrm{BF}$ & 192 & E3 & 227 & & \\
\hline 12 & 18 & 35 & 53 & 58 & 88 & $7 B$ & 123 & $9 \mathrm{D}$ & 158 & $\mathrm{CO}$ & 193 & E4 & 228 & & \\
\hline 13 & 19 & 36 & 54 & 59 & 89 & $7 C$ & 124 & $9 \mathrm{E}$ & 159 & C1 & 194 & E5 & 229 & & \\
\hline 14 & 20 & 37 & 55 & $5 \mathrm{~A}$ & 90 & 7D & 125 & $9 F$ & 160 & C2 & 195 & E6 & 230 & & \\
\hline 15 & 21 & 38 & 56 & $5 B$ & 91 & $7 \mathrm{E}$ & 126 & $\mathrm{~A} 0$ & 161 & C3 & 196 & E7 & 231 & & \\
\hline 16 & 22 & 39 & 57 & $5 C$ & 92 & $7 \mathrm{~F}$ & 127 & A1 & 162 & C4 & 197 & E8 & 232 & & \\
\hline 17 & 23 & $3 \mathrm{~A}$ & 58 & $5 \mathrm{D}$ & 93 & 80 & 128 & $\mathrm{~A} 2$ & 163 & C5 & 198 & E9 & 233 & & \\
\hline 18 & 24 & $3 B$ & 59 & $5 E$ & 94 & 81 & 129 & A3 & 164 & C6 & 199 & EA & 234 & & \\
\hline 19 & 25 & $3 C$ & 60 & $5 \mathrm{~F}$ & 95 & 82 & 130 & $\mathrm{~A} 4$ & 165 & C7 & 200 & EB & 235 & & \\
\hline $1 \mathrm{~A}$ & 26 & $3 \mathrm{D}$ & 61 & 60 & 96 & 83 & 131 & A5 & 166 & C8 & 201 & $\mathrm{EC}$ & 236 & & \\
\hline $1 \mathrm{~B}$ & 27 & $3 E$ & 62 & 61 & 97 & 84 & 132 & A6 & 167 & $\mathrm{C} 9$ & 202 & $\mathrm{ED}$ & 237 & & \\
\hline $1 C$ & 28 & $3 F$ & 63 & 62 & 98 & 85 & 133 & A7 & 168 & $\mathrm{CA}$ & 203 & $\mathrm{EE}$ & 238 & & \\
\hline $1 D$ & 29 & 40 & 64 & 63 & 99 & 86 & 134 & A8 & 169 & CB & 204 & $\mathrm{EF}$ & 239 & & \\
\hline $1 \mathrm{E}$ & 30 & 41 & 65 & 64 & 100 & 87 & 135 & A9 & 170 & $C D$ & 205 & F0 & 240 & & \\
\hline $1 \mathrm{~F}$ & 31 & 42 & 66 & 65 & 101 & 88 & 136 & $\mathrm{AA}$ & 171 & $\mathrm{CE}$ & 206 & F1 & 241 & & \\
\hline 20 & 32 & 43 & 67 & 66 & 102 & 89 & 137 & $A B$ & 172 & CF & 207 & $\mathrm{~F} 2$ & 242 & & \\
\hline 21 & 33 & 44 & 68 & 67 & 103 & $8 \mathrm{~A}$ & 138 & $\mathrm{AC}$ & 173 & DO & 208 & F3 & 243 & & \\
\hline 22 & 34 & 45 & 69 & 68 & 104 & $8 B$ & 139 & $\mathrm{AD}$ & 174 & D1 & 209 & $\mathrm{~F} 4$ & 244 & & \\
\hline
\end{tabular}




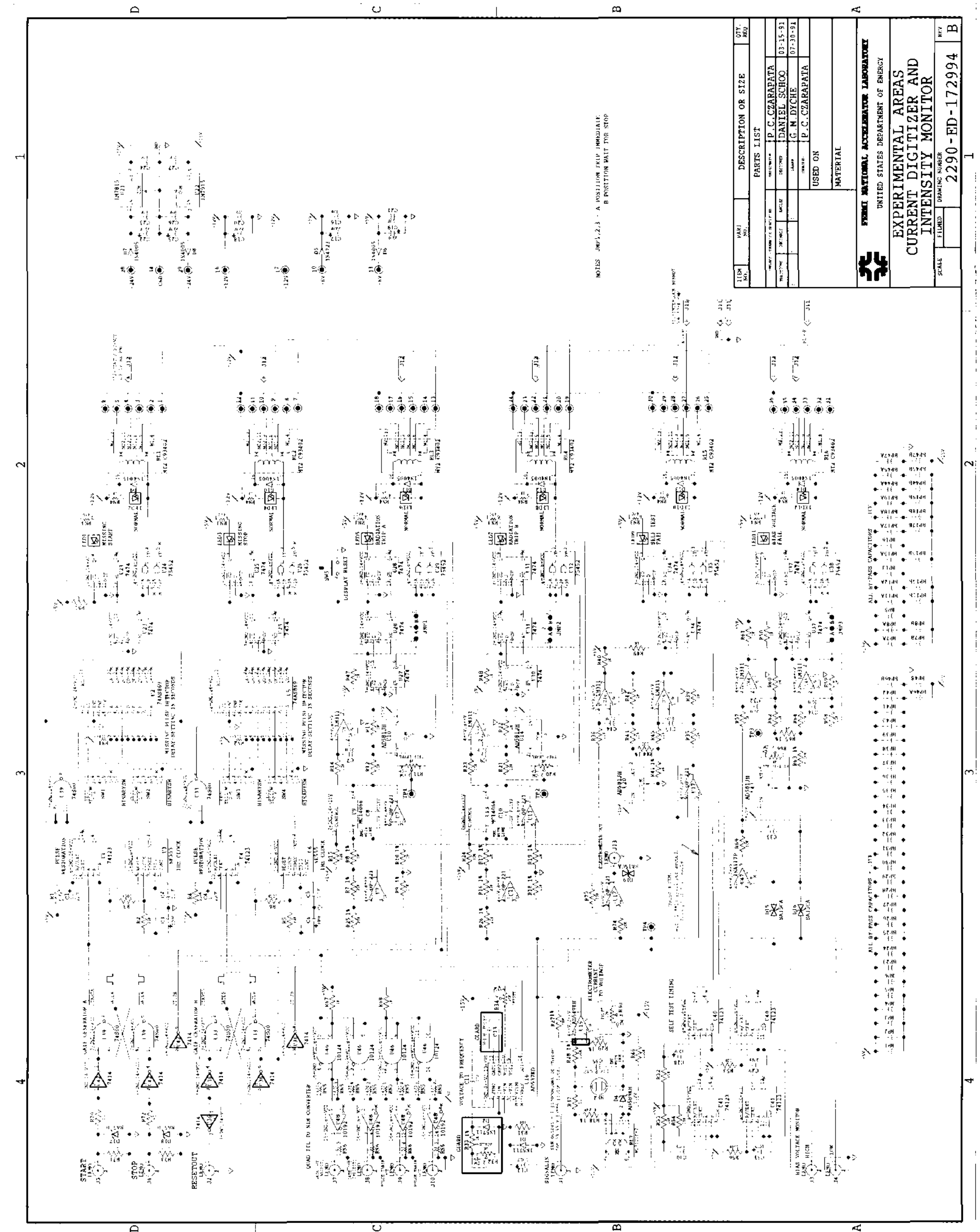

